\title{
Kalibangan: Death from Natural Causes
}

\author{
by ROBERT RAIKES
}

\begin{abstract}
Mr R. L. Raikes is a hydrologist who is head of the firm of Raikes and Partners, consulting engineers in Rome. We recently published an article by him on 'The Mohenjo-daro Floods' (ANTIQUITY, 1965, 196), in which he concluded that Mohenjo-daro and 'inevitably all other sites in the same general area of the Indus flood-plain, were gradually engulfed by mud'. This article provoked discussion and comment in subsequent numbers. $\mathrm{Mr}$ Raikes now considers the end of Kalibangan some time in the $\mathbf{1} 8$ th century $\mathrm{BC}$ and excludes the hypothesis of catastrophic climate change. As he has recently been accused of being a prophet of the New Catastrophism, he says that here it is rather a relief to him to be able, with conviction, to exclude catastrophic climate change.
\end{abstract}

K ALIBANGAN, which has been excavated during recent years-and is still being excavated at the time of writing - by the Archaeological Survey of India, is one of the more important sites of the Harappan Civilization in India (FIG. I). Interim reports on it have been published in Indian Archaeology. The subject of this short paper will in due course be published in full, with the necessary technical details, in Ancient India.

Kalibangan has many things in common with sites such as Mohenjo-daro and Harappa, including virtually the whole repertoire of pottery, flint industry, carved seals, figurines and the like as well as an apparent division into two well-defined areas: a western smaller area, tentatively identified as the citadel area; and a larger eastern area thought to be the residential and business quarter. Its size approaches that of Judeir-jo daro (which is also divided into two areas but in a quite different way)-a Harappan site that I discovered on the Kacchi plain in Sind not far from Jacobabad. Judeir-jo daro is generally regarded as an important site and it seems improbable that Kalibangan was of significantly less importance.

For this reason the principal difference between Kalibangan and the main sites in
Sind and the central Punjab-Mohenjo-daro, Harappa, Chanhu-daro, Judeir-jo daro, Lohumjo-daro, to name but a few-may be of significance. For, whereas the other 'cities' named were constructed largely of burnt brick, Kalibangan was mainly of mud-brick construction. Some use of burnt brick there certainly was but the comparative rarity of it suggests the possibility that the means of producing large quantities of burnt brick did not match the knowledge of how to do so. In other words it suggests a possible lack of abundant fuel.

In $1968 \mathrm{I}$ had the opportunity of carrying out a brief environmental survey of the site and its surroundings through the generosity of the British Academy and the University Museum of the University of Pennsylvania. This generous support as well as the extreme courtesy and cooperation of the Archaeological Survey of India are most gratefully acknowledged.

The basic problem was that of the reason for the abandonment of Kalibangan some time in the I8th century BC. Various possibilities existed; many of them still exist. Only the hypothesis of sudden and dramatic-indeed catastrophic-climate change must, I think, be excluded. The other principal hypotheses are: a sudden diversion of what was once the River 
KALIBANGAN: DEATH FROM NATURAL CAUSES

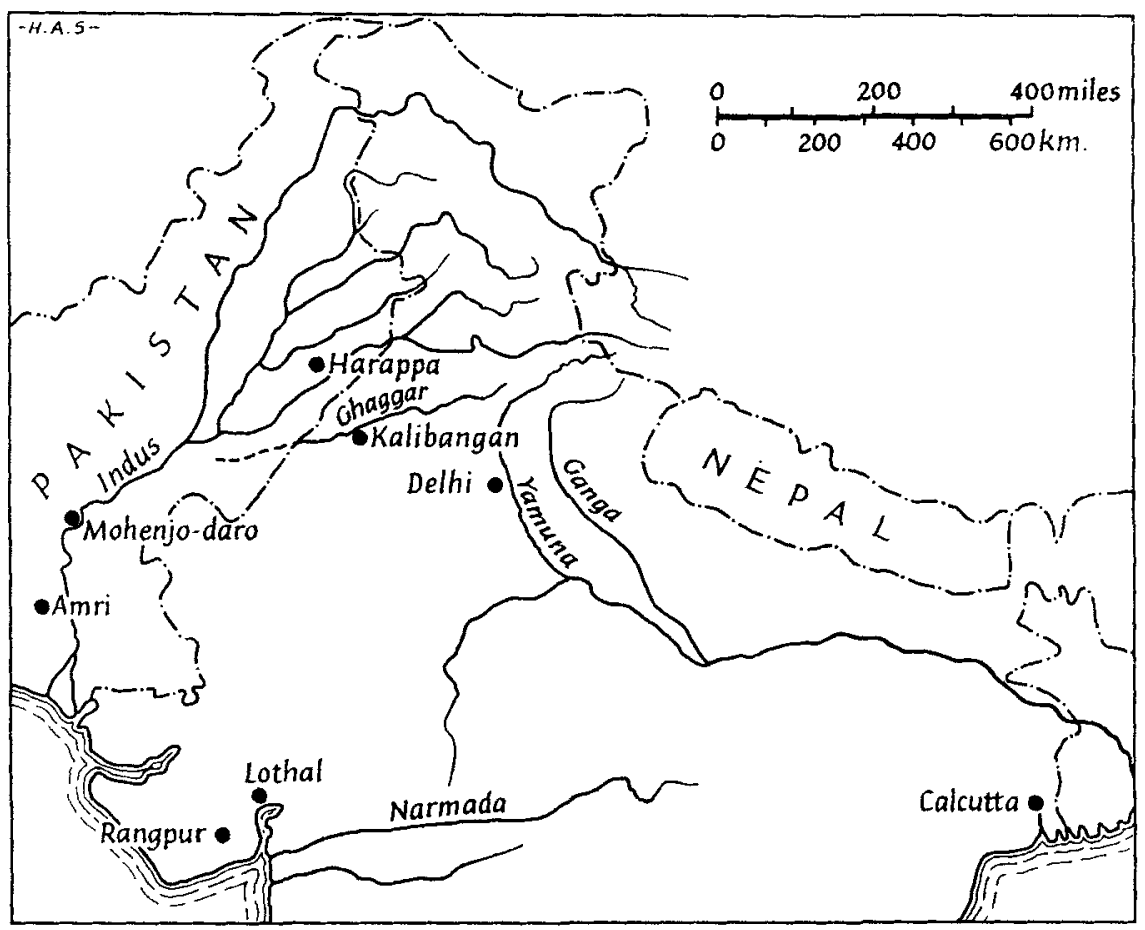

Fig. I. Map showing site of Kalibangan (India)

Ghaggar into the Ganges system; collapse of the whole Harappan Empire consequent on the collapse of Mohenjo-daro and Harappa, for one or other or all of the various explanations put forward; the loss by diversion to its present course of a prehistoric Sutlej; there are probably others. The first of these hypotheses appears to be right.

Through the cooperation of the Archaeological Survey of India and their willingness to consult also the Geological Survey of India I had the advice of both those archaeologistsMr B. B. Lal, then Joint Deputy Director General, and Mr B. K. Thapar-most familiar with the site, and of $\mathrm{Mr} \mathrm{R}$. K. Karanth, Geologist in charge of the whole of Rajasthan and Gujerat.

This is not the place for a full description of the limited drilling programme carried out under the general supervision of Mr Karanth and myself, or of its results (FIG. 2). I do not propose to give definitions of terms such as silty clay and coarse sand that describe the materials found by us. Let it suffice to say that these terms have special significance in the professions in which they are common currency. The special significance attaches to the means by which such materials are deposited.

We found, at a depth of about I I m. below the present flood-plain level, a coarse, greyish sand very similar in mineral content to that found in the bed of the present-day Yamuna (Jumna). It extended over a width at least four times that of the bed of the present-day Yamuna and down to a depth, at one point at least, of $30 \mathrm{~m}$. Within the II m. of deposits overlying this sand we found mainly a material which emerged as a clayey silt but which probably, in the undisturbed state which we could not examine with the equipment available, consists of intercalated silty clay and silt; the existence of some silty clay was borne out by a few tenacious pieces of this material which reached the surface. This material in short is 


\section{ANTIQUITY}

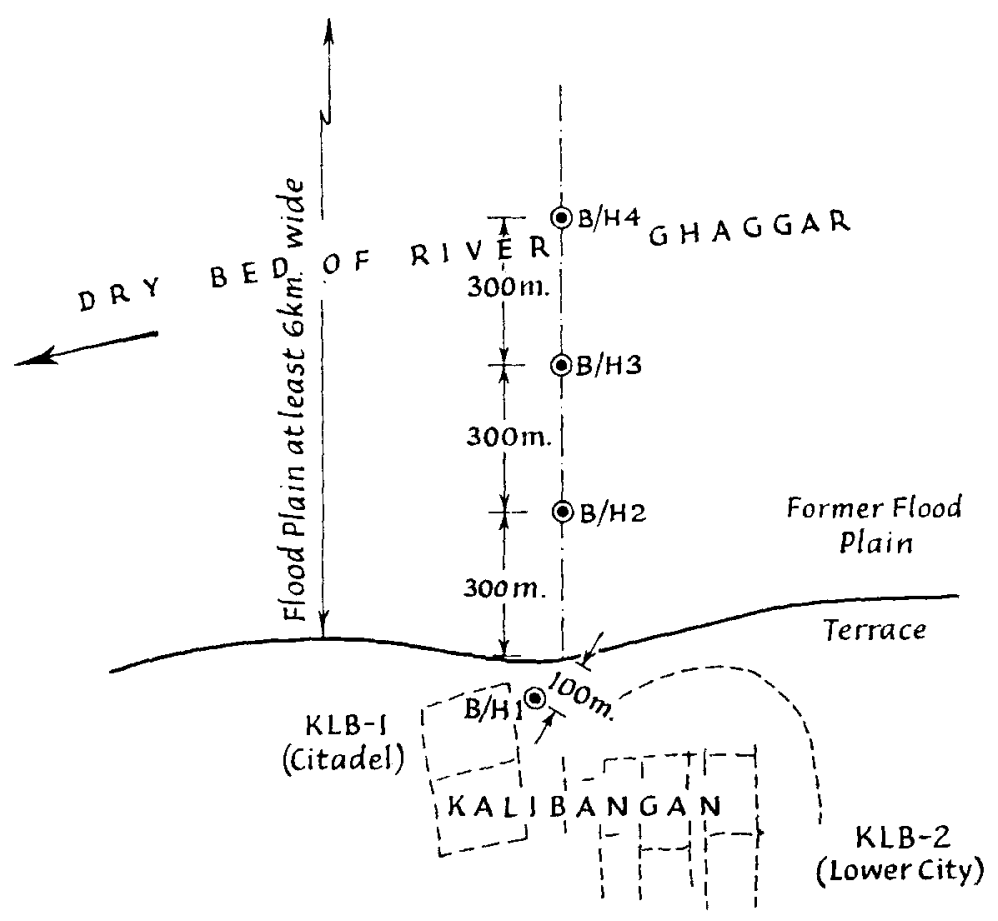

Fig. 2. Plan showing bore-holes

typical flood-plain deposit of the kind being laid down today at a rate of about $2 \mathrm{~m}$. per thousand years.* We also found, at varying depths in the four boreholes, shallow beds of a fine silty sand still containing the grey granitederived material that occurs in the Yamuna, consistent with the various meander channels of an aggrading river (FIG. 3 ).

Unfortunately air photos were not available so recourse was had to available and very detailed large-scale maps of the area. Study of the contours where these are shown and of spotlevels where they are not shown was very revealing. The map study extended far north into the Siwaliks, north-west to the Sutlej and east and north-east to the Yamuna and included the latter down to somewhat south of Indri.

The present Yamuna flood-plain shows on the map almost as clearly as on air photos the

* Sir Claude Inglis, The Behaviour and Control of Rivers and Canals, Government of India Research Publication no. 13 (Poona, 1949). manner in which its meandering channel has migrated across the ro to $15 \mathrm{~km}$. width of the plain. The present Western Yamuna Main Canal evidently incorporates considerable parts of a former channel that followed the extreme western boundary of the plain. Near Indri this western boundary is barely definable in terms of levels, for the plain to the west of the Main Canal slopes gently but continuously towards the Indus system: to the east it slopes gently towards the present Yamuna which occupies a former back-swamp area. The Yamuna today is part of the Ganga (Ganges) system.

The area to the west of the Main Canal indicates numerous small lakes of which many have the typical form of abandoned ox-bow bends. This area was known in earliest historic times by the Sanskrit name of Sarasvati: Mr B. B. Lal informs me that this can be translated as a 'river' reduced to the condition of a chain of pools.

Excavations carried out at an Early Historic 


\section{KALIBANGAN: DEATH FROM NATURAL CAUSES}

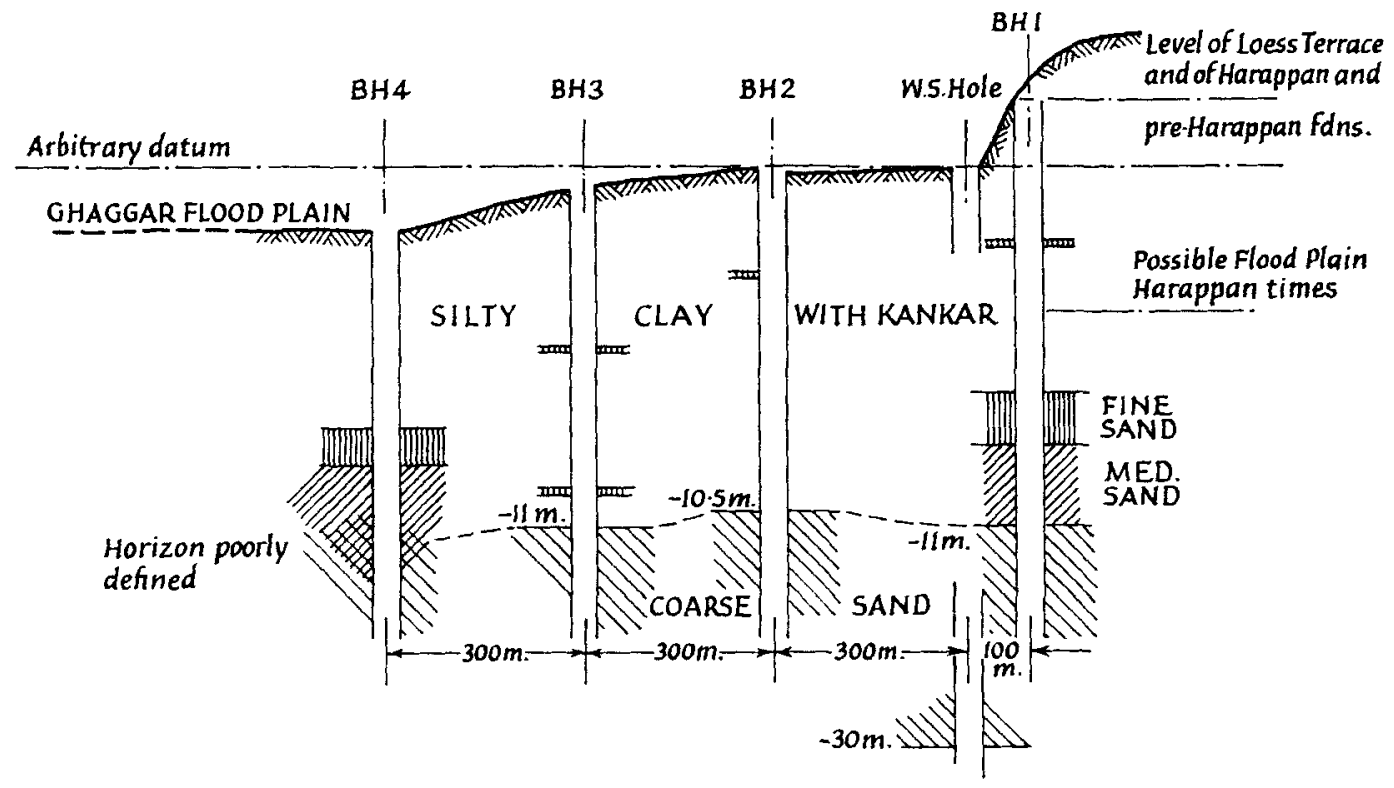

Fig. 3. Schematic cross-section through bed of former Ghaggar River looking upstream

Site near Kalibangan, but situated in the floodplain whereas Kalibangan is above and beside the flood-plain, showed that the lowest level is about $3 \mathrm{~m}$. below the present flood-plain level. This lowest level would correspond with a date of about $100 \mathrm{BC}$. The Early Historic Sites along the Ghaggar remained in general to about $A D 500$ when they were abandoned.

Between these most recent occupations and the Pre-Harappan/Harappan sequence, dated to about $2500-175^{\circ} \mathrm{BC}$, there were other occupants of the Ghaggar Valley. The people responsible for Painted Grey Ware occupied sites along the Ghaggar and also northwards along the relatively small and intermittently flowing stream (the true Ghaggar which has lent its name to the wide and now waterless flood plain that stretches to the Indus) that drains a relatively small area of the Siwalik Hills to the west of the Yamuna. These people had sites in the flood-plain of which the depth to the lowest levels is not known to me; their span of occupation was from about I $100 \mathrm{BC}$ to $500 \mathrm{BC}$.

Even today very occasionally a flood in the modest modern Ghaggar may cause a small and sluggish flow as far downstream as Kalibangan.
No records were available to us at the time to indicate what conditions were like before irrigation of the Ghaggar was started in modern times. The absence of any defined channel in the Ghaggar flood-plain points to a very long period of very attenuated seasonal floods with slow build-up of sediments. An estimate of the rate of such build-up has been made from archaeological evidence which shows that it is slower than that of a perennially overflowing river (that is about $2 \mathrm{~m}$. per $\mathrm{I}, 000$ years).

The general hypothesis, which emerges from the calculations that form part of the full article and from the archaeological evidence that fits so neatly into the picture, is of alternating capture of the Yamuna by the Indus and Ganges systems respectively. That low and almost indiscernible watershed between the two systems and the slow migration westward of the Yamuna acrossits flood-plain under the influence of coriolis force (or deflection force due to the earth's rotation) would result inevitably in a right-bank avulsion somewhere near where Indri now stands. This might not even have required an exceptional flood to cause it. Farther upstream the same westward movement 


\section{ANTIQUITY}

would have been restrained by geological control and sooner or later (but seemingly with a fair degree of regularity) an exceptional floodhaving no right-bank space to accommodate overflow-would have caused a left-bank avulsion and the diversion of the Yamuna to its own back swamp area and the Ganges system. The whole cycle would have tended inevitably to repeat.

In the full technical article calculations are described that indicate an immediate postglacial Yamuna, much enlarged by Himalayan ice-melt, flowing to the Indus system and responsible for the wide buried bed of coarse sand. Between about 6000 and $5000 \mathrm{BC}-$-the figures here are approximate only and do not take account of two major alternatives because they are not relevant to a brief article on Kalibangan - the flow of the river appears to have dwindled to about that of the Yamuna of today. A series of alternating captures by the Indus and Ganges systems then started of which the ones that concern the Pre-Harappan/Harappan period and later occupations are set out in Table I with their results. would have involved a westward diversion, would have been about AD I 100 by which time the people living in the Yamuna Valley downstream of Indri had probably learnt to guard against losing their river by building some kind of embankment.

From the archaeological point of view confirmation of the above comes from the only known late Harappan site (in the Hindan River valley) that lies outside the assumed YamunaGhaggar-Indus system of water-borne communications. At this site the otherwise typical assemblage of Harappan artifacts does not contain any flints. Flint implements, apparently identical with those from sind and central Punjab, are found at Rupar on the Sutlej tributary of the Indus, at all Ghaggar sites, and at one site on the Yamuna upstream of where any westward diversion could have taken place. In other words they are found at all sites connected, or that could have been connected, by water with the Indus: as there are no sources of flint in the Yamuna-Ghaggar area near New Delhi it is probable that the material was brought from Sukkur. With the drying up of the Ghaggar

Table I

Westward diversion to Indus 2500-1750 BC (coinciding with Harappan occupation)

Eastward diversion to Ganga 1750-1 $100 \mathrm{BC}$ (coinciding with abandonment)

Westward diversion to Indus I roo-500 BC (coinciding with Painted Grey Ware Sites)

Eastward diversion to Ganga 500-100 BC (coinciding with abandonment)

Westward diversion to Indus $100 \mathrm{BC}-500 \mathrm{AD}$ (coinciding with Early Historic)

Eastward diversion to Ganga in about $A D 500$ (coinciding with abandonment)

The dates are consistent with differential rates of aggradation: $2 \mathrm{~m}$. per $\mathrm{I}, 000$ years during periods of 'perennial Ghaggar'; $1 \cdot 2 \mathrm{~m}$. per 1,000 years during periods of 'dry Ghaggar'. The total depth deposited is consistent with an original period of 'perennial Ghaggar' (of Yamuna proportions) plus one other, and with two periods of 'dry Ghaggar' all before the westward capture that made the Harappan settlement possible.

The next probable date in the series, which the whole line of communication to the Ganga would have been cut. It is a semi-desert area and could only have been settled and travelled through with the help of a perennial river.

It does not follow that the sites along the Ghaggar would automatically have been abandoned immediately the Ghaggar was diverted. The archaeological evidence indicates a decreasing size of settlement in the upper and latest levels and so a decreasing population: a much-decreased population could possibly have 


\section{KALIBANGAN: DEATH FROM NATURAL CAUSES}

eked out some kind of existence on the small seasonal floods of a Ghaggar similar to that of today. Abandonment would have been forced on this remnant by shortage of year-round drinking water. The inevitably high water table sustained by a perennial Ghaggar and its floods would have fallen-probably quite quickly-to a level beyond reach of Harappan wells when the source of recharge disappeared.

One suspects that survivors of the disaster moved upstream to the Ganga system, where they founded flintless settlements, or downstream to the Indus according to the distances involved.

The Pre-Harappan earliest settlement is dated to 'a little after $2500 \mathrm{BC}$ '; its duration is not known but there seems to have been a period during which both Pre-Harappans and Harappans were occupying the site together. The postulated westward diversion of the Yamuna that made this settlement possible involves the longest period in the sequence and may be somewhat overestimated. Whether it is or not it seems likely that the sudden appearance of a new Indus tributary somewhere around 2500$2400 \mathrm{BC}$ created new living space into which people moved immediately. The Pre-Harappan first occupants appear, on the evidence of their flint industry and its source of material in the region of Sukkur, to have come from downstream either from Sind or from areas already in contact with northern Sind. There is no reason and no need to equate them with the people of Kotdiji or of Pre-Harappan Amri beyond postulating cautiously that they were probably at about the same state of cultural evolution as those people. They had two things in common with Kotdijians and Amrians, however: an apparent preference for sites on relatively high ground outside but flanking the flood-plain of their river, and reliance to a great extent on mud brick or other natural material for construction. If, as the dates suggest, the Pre-Harappans at Kalibangan were closely followed by Harappans these latter would have arrived very soon after the establishment of the new river. Now this new river, flowing on earlier relatively impermeable flood-plain deposits overlying a dried-out coarse sand aquifer, could have taken a considerable time to recharge this aquifer. Present-day irrigation and occasional floods appear to have an almost negligible effect on the aquifer. It could well have required a century or more of infiltration to reach the kind of equilibrium enjoyed by a perennial river. There would have been two direct consequences. The first would have been a corresponding delay in the establishment of the typical Acacia Arabica/Tamarisk gallery forest that requires a shallow water table, and so a corresponding delay in availability of fuel for making bricks. The second would have been the need to rely at first on river water rather than on wells for drinking. I suggest that the great use of mud brick was due to settlement having started very soon after the rebirth of the Ghaggar river and that it was continued simply because it was found to be cheap and effective.

The next stage of this investigation is a purely archaeological one and will, I hope, be started shortly. It will involve a detailed reconnaissance of the ancient course of the Sarasvati which, until now, has not been adequately explored. The part involved lies between the point (far east of Kalibangan) where the Chautang Nadi leaves the Ghaggar flood-plain, to form a southerly loop rejoining the Ghaggar still to the east of Kalibangan; and the Yamuna.

A detailed reconnaissance of the Yamuna from Indri down to the Hindan junction would also be worth while.

If Harappan sites are found along that part of the ancient Sarasvati, complete with the typical flint industry, the hypothesis of a Yamuna diversion during Pre-Harappan and Harappan times should satisfy all but the most exacting of critics. Other diversions of the Yamuna before the archaeological period and during Painted Grey Ware and Early Historic occupations are not strictly germane to this study but they too would become more acceptable.

It may be asked whether the cutting-off of the Ghaggar tributary may have contributed to the general decay of settlements based on the Indus. I am inclined to think that the effect would have been very minor in Sind and nil at Harappa itself. In Sind it would merely have been one more nail in a coffin already well closed. 